\title{
On Perfective -le in Mandarin Chinese: Theoretical and Pedagogical ISSUES
}

\author{
I-hao WOO \\ University of Colorado Denver, United States \\ i-hao.woo@ucdenver.edu
}

\begin{abstract}
Although Mandarin Chinese perfective -le has been extensively studied in the literature, views on its linguistic properties nevertheless remain controversial. In this study, I first discuss the temporal function of perfective -le and provide an alternative account. In the spirit of Klein's (1994) approach regarding different temporal intervals, I demonstrate that the core function of this suffix is to indicate that one event occurs after another. I then address the issue of the English translation of perfective $-l e$ in a Chinese as a foreign or second language class and argue that English present perfect construction may not represent the translation correctly. The proposal not only gives a more straightforward definition of the perfective -le, but also provides a simpler way for the instruction of the suffix.
\end{abstract}

Keywords: Chinese perfective -le; tense and aspect; temporal intervals; Chinese language pedagogy

\section{Povzetek}

Kljub temu, da je kitajski dovršni -le že dodobra raziskan, mnenja o njegovih jezikovnih lastnostih ostajajo različna. $V$ tej študiji se najprej osredotočamo na časovno funkcijo omenjenega dovršnika in predlagamo drugačen pristop. Po Kleinovi metodi različnih časovnih intervalov (Klein, 1994) prikažemo, da je ključna naloga pripone -le sporočanje, da se en dogodek pojavi po drugem dogodku. Zatem obravnavamo še prevode dovršnega -le v angleščino, kjer ugotavljamo, da njegova pretvorba v obliko sedanjega dovršnika (angl. present perfect) ni najbolj ustrezna. V članku predlagamo novo definicijo kitajskega dovršnega -le, ki hkrati omogoča enostavno razlago pri poučevanju.

Ključne besede: kitajski perfektivni -le; čas in aspekt; časovni intervali; poučevanje kitajskega jezika

\section{Introduction}

As a language that is pragmatically driven (Li \& Thompson, 1981), Chinese grammar shows several inconsistent properties. For example, verbal suffix -le, which functions as a perfective morpheme (e.g., Smith, 1997; Huang, Li \& Li, 2009), is required in a 
sentence like (1a); however, in a sentence such as (1b), which is modified by the same temporal adverbial zuotian 'yesterday' the suffix is not required:
(1)
a.
Wangwu zuotian

\section{在家}
写了
一封信。
Wangwu yesterday
zai jia
xie-le
yi feng xin.
'Wangwu wrote one letter at home yesterday.'
b. 王五昨天 在家 写信。
Wangwu zoutian zai jia xie xin.
Wangwu yesterday at home write letter
'Wangwu wrote letters at home yesterday.'

A related problem regarding Chinese perfective -le is its interpretation in English. Observe the sentences in (2) and (3) below:

(2) 李四吃了 三碗炒饭。

Lisi chi-le san wan chaofan.

Lisi eat-PRF three $\mathrm{CL}$ fry rice

i. 'Lisi ate three bowls of fried rice.'

ii. 'Lisi has eaten three bowls of fried rice.'

(3) 李四昨天 吃了 三 碗炒饭。

Lisi zuotian chi-le san wan chaofan

Lisi yesterday eat-PRF three $\mathrm{CL}$ fry rice

i. 'Lisi ate three bowls of fried rice yesterday.'

ii. *'Lisi has eaten two bowls of fried rice yesterday.'

As shown, the sentence in (2), which does not contain any temporal adverbials, can have two different English interpretations according to some studies and textbooks: one interpretation with English past-tense and the other with English present perfect. In contrast, a sentence like (3), which has a temporal adverb zuotian 'yesterday' can only have the past-tense interpretation given that the adverbial yesterday is incompatible with the present perfect in English. This constraint seems to suggest that -le is not completely equivalent to the perfect construction in English (at least, the present perfect) given that this suffix can appear in a sentence containing a temporal adverbial such as zuotian 'yesterday'. Moreover, according to Portner (2003), English perfect construction has additional pragmatic contributions in addition to its semantic properties. My observation is that perfective -le does not have similar pragmatic contributions and I will give more details later in Section 3.

The sentences in (1) to (3) demonstrate the grammatical complexity of perfective -le in Chinese. Although numerous studies have discussed both the theoretical aspect of the suffix (e.g., Shi, 1989; Smith, 1997; Sybesma, 1999; Wu, 2004; Ljungqvist, 2007; Soh \& Gao, 2007; Huang, Li \& Li 2009; among many others) and CFL/CSL learners' acquisition of the suffix (e.g., Wen, 1997; Teng, 1999; Duff \& Li, 2002; Ke, 2005; among 
others), nevertheless, the grammatical inconsistency of perfective -le and its correct translations presented above still cause CFL/CSL learners some challenges. As a result, how to instruct the grammar in a more systematic way is one of the priorities that $\mathrm{CFL} / \mathrm{CSL}$ instructors must consider in the classroom.

This study attempts to address issues related to the semantic properties of Chinese perfective -le and problems that CFL/CSL instructors may face while teaching the translation of the verbal suffix. I will first discuss the main semantic function of the suffix. I follow the proposals regarding grammatical items related to temporal relations like tense and aspect made by Klein (1994), Demirdache and Uribe-Etxebarria (2004, 2007, 2014), and Arche (2014) and argue that the main function of -le is simply to order two temporal intervals. I will then discuss the proper English translation of perfective -le. I deliberate the difference between the perfective aspect and the perfect construction and demonstrate that a clarification of the differences between these two grammatical items will assist CFL/CSL learners' acquisition of perfective -le.

The paper is organized as follows. After giving an introduction of the scope of the current study in section 1, I review previous studies related to the current discussion in section 2 . In section 3,1 address theoretical and pedagogical issues regarding the suffix -le and discuss the core function of this suffix and show several problems of using grammatical terms in English to teach this suffix. Several pedagogical implications about perfective -le are presented in Section 4. Finally, section 5 gives a summary and conclusions.

\section{Theoretical background}

Previous studies have argued that the main function of the suffix -le is to signal the perfective aspect in Mandarin Chinese (e.g., Li \& Thompson, 1981; Smith, 1997; Huang, Li \& Li, 2009; among many others). As demonstrated in the sentences in (2) and (3), a sentence with this suffix is sometimes translated into the perfect construction in English in some textbooks. However, the perfective aspect and the perfect construction are in fact two different types of grammatical constructions. To clarify the confusion, I review several previous studies that have dealt with these two types of grammatical constructions in this section. However, there is a considerable literature on this topic. My main goal here is not to cover the full range of connotative and contextual meanings, but to present the basic meaning and form of these two types of grammatical constructions. 


\subsection{The perfective aspect}

The term aspect traditionally refers to grammaticalized viewpoints like the perfective aspect and the imperfective aspect. Recently, the range of the term has broadened so that it also includes temporal properties of situations or situation types (i.e., different types of verbs). According to Comrie (1976), the perfective aspect indicates the view of a situation as a single whole, without distinction of the various separated phrases that make up that situation. Similarly, Smith (1997) argues that the perfective aspect mainly focuses on a situation in its entirety, including both initial and final points. Therefore, according to Smith, the general schema for the perfective viewpoint aspect is given in (4) below:

(4) The general schema for the perfective aspect

I $\quad \mathrm{F}$

$/ / / / / / / / / / / / /$

The capitalized ' $\mathrm{I}$ ' in (4) represents the 'initial point' of a situation, and ' $\mathrm{F}$ ' represents the 'final point.' As shown, a sentence with the perfective aspect focuses on a situation as a whole; the span of the perfective includes both the initial and the end points of the situation. In informal terms, it represents a closed event.

Smith (1997) further claims that the perfective aspect is incompatible with an assertion whose event is ongoing. The perfective viewpoint indicates that the event it interacts with is either terminated or complete, depending on the type of verb class to which the event belongs. ${ }^{1}$ For example, the English perfective aspect indicates that an event is terminated when it is combined with an Activity, as demonstrated in (5a). John's swimming must be terminated at the moment of the utterance. In contrast, combining with a telic event such as an Accomplishment or Achievement, the perfective aspect indicates that the event is completed, as demonstrated by the sentences in (5b) and (5c):

(5) a. John swam.

(Activity)

b. John wrote a letter. (Accomplishment)

c. John won the race. (Achievement)

In contrast, stative sentences with the perfective aspect are flexible in interpretation. For example, observe the sentence in (6): ${ }^{2}$

(6) Sam owned three mansions. (State)

\footnotetext{
${ }^{1}$ The different types of verbs presented here are based on Vendler's (1967) classification. According to Vendler, verbs can be generally grouped into four classes depending on their aspectual properties: Activity, State, Accomplishment, and Achievement.

${ }^{2}$ Note that the sentence in (6) is perfective although it does not contain an overt perfective marker. According to Demirdache and Uribe-Etxebarria (2004), sentences like (6) in English contain morphological tense, but do not have morphological aspect.
} 
On one reading, (6) conveys an open interpretation; that is, the state of Sam's owning three mansions has not ended and continues into the present; therefore, it is not contradictory to say John owned three mansions before, and he still does now. ${ }^{3}$ The sentence in (6) is also compatible with a situation in which the state of Sam's owning three mansions has ended before the speech time. This is the closed interpretation of (6); therefore, one can say without contradiction that Sam owned three mansions, but he no longer owns them.

Morphologically, according to Comrie (1976), languages use specific forms to express the perfective aspect. For example, English generally uses the simple past to express the perfective viewpoint aspect. The sentences in (5) and (6) all contain this form. Other languages such as French have more than one perfective form. For example, Smith (1997) indicates that the French passé composé and passé simple both convey the perfective viewpoint aspect.

Finally, many previous studies have attempted to map the perfective aspect and the imperfective aspect onto syntax. For example, Travis $(2005,2010)$ argues that there is a functional phrase, Outer Aspect Phrase, that is projected above the VP, and it is this functional phrase that encodes the perfectivity of an event. According to Travis, when a sentence has the perfective aspect, the head of Outer Aspect Phrase contains the feature [+perfective]. In contrast, when a sentence has the imperfective aspect, the functional phrase contains the feature [-perfective]. Therefore, the syntactic distributions of these two aspect phrases outlined by Travis can be represented in (7):
(7)
[OutAspP ${ }_{( \pm) \text {PERFECTIVE }}[\mathrm{VP} \ldots$
$\left[\begin{array}{ll}\mathrm{VP} \ldots & ]\end{array}\right]$

As illustrated, Outer Aspect Phrase (OutAspP) is a functional phrase that is projected above VP. It is encoded with the feature related to (im)perfectivity.

According Huang, Li \& Li (2009), like English, Chinese also allows recursive functional phrases related to aspect. The sentence in (8) offers an example in English, and (9) in Chinese:

(8) Mary has been eating the roast duck.

(9) 李四 没有吃过牛肉。

Lisi mei you chi-guo niurou.

Lisi not have eat-guo beef

'Lisi did not eat beef (before now).

\footnotetext{
${ }^{3}$ However, the more salient interpretation for the open reading is that Sam owns three mansions that are different from previous ones; nevertheless, the sentence may still indicate that Sam owns the same three houses.
} 
As showed in (8), the sentence contains both the perfective auxiliary have and the progressive be. This indicates that there are two functional phrases related to viewpoint aspect in the inflectional domain. Similarly, the Chinese sentence in (9) also conveys two types of aspectual information. First, the particle you 'HAVE' signals the perfectivity of the event. Second, the Experiential -guo indicates a past experience (Li \& Thompson, 1981). To account for the coexistence of the two types of aspectual particles in the sentence in (9), Huang, Li \& Li (2009) suggest that a clause may contain as many aspectual phrases because there are identifiable aspectual markers.

\subsection{The perfect construction}

The perfect construction is generally used for constructions that have a temporal and aspectual meaning, whether or not they are involved with tense. The sentences in (10) give a demonstration of sentences containing the perfect construction in English:

(10) a. John has eaten three apples.

(present)

b. John had eaten three apples when Mary entered the living room. (past)

As demonstrated, although the two sentences $n$ (10) have different tenses, they both contain the perfect construction, which is morphologically expressed by the auxiliary verb have and the participle en, attached to the main verb.

According to Smith (1997), there is a difference between the perfect construction and the perfective aspect. The perfect refers to a special construction with particular temporal and aspectual characteristics; the perfective aspect, on the other hand, refers to a closed aspectual viewpoint. In general, language uses a specific form to express the prefect construction. For instance, as presented, English often uses the auxiliary verb have along with the participle en to convey the perfect value. The main semantic function of the perfect is to indicate that a given situation occurs or holds prior to the Reference Time (RT). The sentences in (11), taken from Smith's work, give a demonstration:

(11) a. Now John has arrived.

b. Last Saturday John had (already) arrived.

(present)

c. Next Saturday John will have already arrived. (future)

As shown, the three sentences in (11) all contain the perfect construction with different types of tenses. However, in all these three examples, the event [John arrive] occurs before the RT. In (11a), John's arrival occurred before the RT, which is modified by the temporal adverb now. In other words, John's arrival occurred before the sentence is produced. In contrast, the RT in (11b) is last Saturday and John's arrival took place before last Saturday. Finally, the perfect can appear in the future as (11c) shows. In this case, John's arrival will occur any time before next Saturday. 
In addition to the temporal function discussed above, there are several different "special" readings that are associated with the perfect construction. Observe the sentences in (12) below:

(12) a. Mary has lived in London for five years. (Continuative Perfect)

b. Mary has read Dream of the Red Chamber. (Resultative Perfect)

As can be seen, a sentence like (12a), containing a stative event live and the adverbial for 5 years, has a continuative perfect reading in which Mary very likely still lives in London when the sentence is produced. Previous studies such as Bäuerle and von Stechow (1980) and Portner (2003) have argued that the syntactic position of the adverbial and the semantic features of a stative event can explain the continuative reading signaled by the adverbial.

Another additional reading that is associated with the perfect construction is the 'resultative' reading and the sentence in (12b) above gives a demonstration. The sentence has a resultative perfect reading in which Mary's reading of the novel has caused some result and some effect to the current situation. For example, Mary can give an introduction about the complexity of Chinese family relationships because she has read the novel.

One final grammatical constraint shown by the English present perfect is its incompatibility with purely past-time adverbials like yesterday in (13a):

(13) a. *John has eaten two sandwiches yesterday.

b. John has eaten two sandwiches today.

As (13) shows, the present perfect is only compatible with the adverbial today but not yesterday. Previous studies such as Giorgi and Pianesi (1997) provided a syntactic approach and argued that the sentence in (13a) is unacceptable due to a syntactic incompatibility between the present tense and past adverb. This approach also explains why (13b) is acceptable. However, studies such as Portner (2003) argue that the incompatibility is due to pragmatic reasons.

That the present perfect and past-tense like adverbs such as yesterday are incompatible in English has important pedagogical implications for Chinese perfective -le. As stated in section 1, the suffix has been translated into the present perfect in English by some studies and textbook. However, as demonstrated in (1), perfective -le is compatible with past-tense like adverbs such as zuotian 'yesterday'. This raises the question whether or not sentence containing this suffix should be translated into English present perfect. In section 3, I will show that sentences like (2) should not be translated as English perfect construction as perfective -le in Chinese does not have the same pragmatic properties as English perfect construction. 


\subsection{Klein's (1994) temporal intervals}

With respect to the functions of perfective -le in Chinese, the theoretical framework assumed in this study is based on what has been developed by Klein (1994), Stowell (1996, 2007), Demirdache \& Uribe-Etxebarria (2004, 2007, 2014) and Arche (2014). In this framework, it is argued that temporal and aspectual interpretations are obtained by virtue of the relations that temporal intervals build between one another. The relationships are established by the syntactic categories of tense and aspect, which are argued to be dynamic predicates that contain the same semantic primitives; however, these two predicates differ in that they order different temporal intervals. The set of time-denoting intervals that tense and aspect order consists of the following in (14):

(14) a. The Reference Time (REF-Time): the speech time in a matrix clause.

b. The Assertion Time (AST-Time): the time for which an assertion is made.

c. The Event Time (EV-Time): the time at which the event/state denoted by the VP occurs or holds.

The semantic content of tense and aspect is defined as the ordering predicates after, before or within. The main function of tense is to order the REF-T and the AST-T (Klein, 1994), and the one of aspect is to order the AST-T with respect to the EV-T (Demirdache \& Uribe-Etxebarria, 2000, 2004). For example, past tense indicates that the REF-T is after the AST-T; However, with the same ordering function (i.e., after), the perfect construction indicates that the REF-T is after the EV-T. Therefore, a sentence such as (15), which contains past tense and the perfect construction has the temporal structure in (16):

(15) John had eaten three apples when Mary entered the living room.

(16) Temporal Structure of (15)

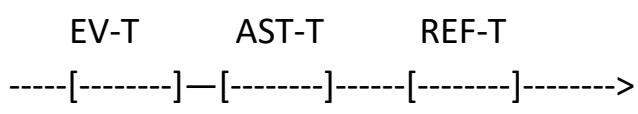

The three temporal intervals expressed in (15) are the follows: (a) the EV-T: the time at which John ate three apples; (b) the AST-T is the time at which Mary entered the living room; (c) the REF-T: the time at which the sentence is produced. As the sentence contains past tense, the REF-T occurs after the AST-T. In other words, the time at which Mary entered the living room occurred before the sentence is produced. On the other hand, the perfect construction indicates that the AST-T occurs after the EV$\mathrm{T}$; therefore, John's eating three apples occurred before Mary's entering the living room.

However, English sentences with the perfective aspect is a little more complicated given that the aspect is not morphologically expressed (Smith, 1997). The sentence in 
(17a) gives an example that contains the perfective aspect and its temporal structure is represented in (17b):

(17) a. John ate three apples.

b. Temporal Structure of (17a)

EV-T REF-T

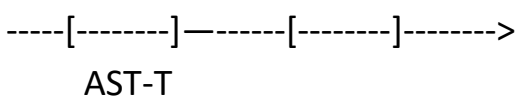

AST-T

As demonstrated, two of the three temporal intervals are clearly expressed in (17a). They are: the REF-T (i.e., the time at which the sentence is produced), and the EV-T (i.e., the time at which John ate three apples). As far as the AST-T is concerned, I follow Arche (2014) and assume that the ordering function of the perfective aspect is to signal that the AST-T overlaps the EV-T; therefore, the AST-T is also the time at which John ate three apples. However, English morphology does not overly express this overlapping relation. As the sentence contains past tense, the REF-T occurs after the EV-T/AST-T.

The ordering functions of different types of grammatical items related to tense and aspect discussed in this sub-section provides the current study with a valuable insight regarding the semantic functions of perfective -le in Mandarin Chinese. As a marker of perfective aspect, -le must express a certain type of ordering relation between two different temporal intervals. In section 3, I will give a detailed analysis of the ordering functions that perfective -le contains.

\section{Theoretical and pedagogical issues of perfective -le}

\subsection{The ordering function of perfective -le}

Syntactically, the perfective suffix -le directly follows a verb and before the object, if any. Its semantic contributions have received considerable attention yet its status still remains controversial. While many scholars have claimed that $-l e$ is a perfective marker that signals either completion or termination of an event (e.g., Chao, 1968; Smith, 1997; Soh \& Gao, 2007), some have proposed that this suffix indicates the boundedness of an event (Li \& Thompson, 1981; among others). Still others, Lin (2003) and Sybesma (1999), for example, claim that -le signals realization or inception of an event.

As we have discussed in section 2.3, grammatical elements related to time such as tense and aspect build up a temporal relationship between two different temporal intervals. In the spirit of Klein (1994), Demirdache and Uribe-Etxebarria $(2007,2014)$ and Arche (2014), I would like to propose that the core function of -le is to build up a temporal relation between two intervals. However, for the sake of simplicity, I use the 
term event/action instead of the time at which an event/action occurs assuming that an event/action must be associated with a certain temporal interval. Therefore, I argue that -le is a perfective marker that indicates an event/action occurs after the other. The temporal relation built up by -le can be represented by (18) below: ${ }^{4}$

(18)

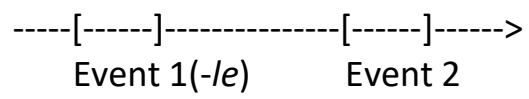

The chart in (18) demonstrates that the suffix builds up a temporal relation between two different events/actions. The event/action denoted by the verb to which -le is attached must occur before the other. In other words, the suffix -le indicates that there is one event (i.e., Event 2) that occurs after the other (i.e., Event 1). The temporal relation expressed by -le may occur in the past and the future. This aspectual property then explains why -le is not a past tense marker given that it may appear in the future as well.

Let us now discuss the temporal relation built by -le in different temporal situations. The sentence in (19a) gives an example in which -le appears in a situation in the past and $(19 \mathrm{~b})$ is its temporal structure:
a. 李四 昨天
看了 那
Lisi zuotian
kan-le
na
个
电影 才
回家。
Lisi yesterday watch-PRF that
ge dianying cai huijia.
'Lisi went home after watching that movie yesterday.'

b.

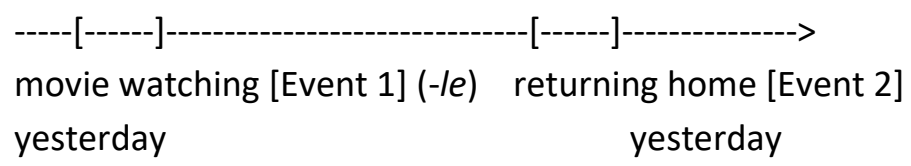

The sentence in (19a) includes two events that are clearly stated: the moviewatching event and the home-returning event. The chart in (19b) shows that the homereturning event (Event 2) occurred after the movie-watching event (Event 1 ). This temporal relation is contributed by perfective -le. As shown, the two events can both be modified by the adverb zuotian 'yesterday'. What the verbal suffix -le does here is to indicate that the second event occurred after the first one, which also took place yesterday.

As argued by previous studies such as Li and Thompson (1981) and Smith (1997), the suffix -le can be used in the future as well. The sentence in (20a) gives an example:
a. 李四 明天
看了
那 个 电影 'Lisi will come home after watching the movie tomorrow.'

\footnotetext{
${ }^{4}$ See Petrovčič (2009) for similar charts and representations of -le.
} 
b.

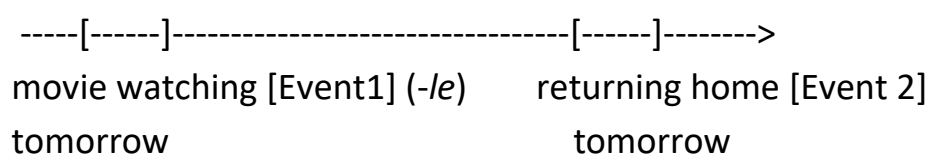

As can be seen, the sentence in (20a) contains two salient events: (a) the moviewatching event (Event 1 ) and (b) the home-returning event (Event 2). As the perfective is attached to the verb that denotes Event 1, the temporal relation between the two events is that Event 2 occurs after Event 1 as demonstrated in (20b).

The two examples in (19) and (20) both contain two events that are clearly stated in the sentence. However, the suffix -le may also appear in a sentence in which only one event is clearly stated. The sentence in (21a) gives a demonstration:

(21)
a. 李四 看了 那个 电影。
Lisi kan-le na ge dianying
Lisi watch-PRF that $\mathrm{CL}$ movie
'Lisi watched that movie.'

b.

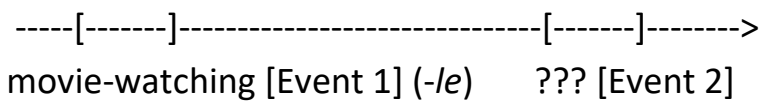

As can be seen in (21a), there is only one event in the sentence; that is, the moviewatching event (Event 1). Given that the suffix -le indicates there is another event that is after Event 1, there must be another event that is associated with the sentence. However, this event is not clearly stated. In the spirit of Demirdache and UribeEtxebarria $(2007,2014)$, I argue that the event that occurs after the moving-watching event is the sentence-producing event; that is, the speaker's production of the sentence. I use the word speaking to represent this event. Therefore, -le indicates that the speaking event occurs after the movie-watching event, which occurred in a certain time period that is prior to the speaking event. The chart in (22) represents the relationship between the two events.

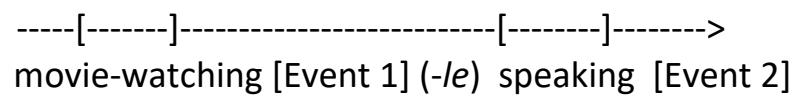

The same argument can be used to explain a sentence such as (23a), which contains a temporal adverbial such as zuotian 'yesterday':

$\begin{array}{lllll}\text { a. 李四 昨天 } \quad \text { 看了 } & \text { 那 } & \text { 电影。 } \\ \text { Lisi zuotian kan-le } & \text { na ge } & \text { dianying } \\ \text { Lisi yesterday watch-PRF that } & \mathrm{CL} \text { movie } \\ \text { 'Lisi watched that movie yesterday.' }\end{array}$


b.

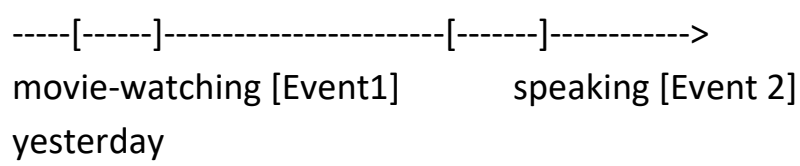

As can be seen in (23a), the adverbial zuotian 'yesterday' is used to modify the movie-watching event. Like (22a), the second event is the event of making the sentence. In this case, the suffix again indicates that the speaking event occurs after the movie-watching event. Different from (22a), the movie-watching event must have occurred sometime yesterday as it is modified by this temporal adverb. However, the same adverb yesterday cannot be used to modify the speaking event given that the event is always at the present time.

The temporal relation built up by the suffix -le is straightforward. When a sentence with -le contains two events that are clearly stated, the perfective marker indicates that the one event is after the other. On the other hand, when a sentence only has one clearly stated event like (23a), the perfective marker indicates that the speaking event occurs after the main event of the sentence.

\subsection{The English translation of perfective -le}

In this sub-section I discuss the issue of whether or not perfective -le should be translated into an English sentence with the perfect construction.

Recall that the main semantic function of English perfect construction is to build up a temporal relation between the event time (EV-T) and the assertion time (AST-T); it indicates that the assertion time occurs after the event time (Demirdache \& UribeEtxebarria, 2007, 2014). This temporal relation seems to be the same as perfective -le given that this suffix also builds up an after relation as proposed in section 3.1. Nevertheless, also recall that in addition to the ordering function, there are several different "special" readings that are associated with the perfect construction as demonstrated by sentences in (12) in session 2.2. It is then interesting to see whether or not the suffix -le also conveys these special meanings. If it does, we can then conclude that the perfect construction is one of the good interpretations of a sentence containing the suffix; in contrast, if it does not convey these additional meanings, we then need to be more cautious while instructing the interpretations of the suffix.

I begin the discussion on the continuative perfect reading of a sentence such as (12a), repeated as (24) below:

(24) Mary has lived in London for five years.

(Continuative Perfect)

As discussed in session 2, the sentence in (24) has a continuative perfect reading in which Mary very likely still lives in London when the sentence is produced. The Chinese 
sentence in (25), which contains the suffix, has similar semantic environment in which the same verb (zhu 'to live') and adverbial wu nian '(for) five years' are also included:

(25) 李四 在 北京 住了 五 年。
Lisi zai Beijing zhu-le wu nian.
Lisi at Beijing live-PRF 5 year
'Lisi lived in Beijing for 5 years.'

Based on my own ears and my consultations with several native speakers, the sentence in (25) does not have a continuative reading. It only means that Lisi lived in Beijing sometime in the past for five years and no longer lives there anymore; therefore, the simple past-tense translation in English more properly represents the meaning of the sentence. This seems to suggest that perfective -le does not have the same pragmatic function as English present perfect does. Moreover, the two sentences in (26) give additional support:
a. 李四 在 北京 住了 五 年了。(continuative) Lisi zai Beijing zhu-le wu nian le. Lisi at Beijing live-PRF 5 year SFP 'Lisi has lived in Beijing for 5 years.'
b. 李四在 北京 住 五 年了。 (continuative) Lisi zai Beijing zhu wu nian le. Lisi at Beijing live 5 year SFP 'Lisi has lived in Beijing for 5 years.'

In (26a) there are two different les, one being perfective -le immediately after the main verb and the other being Sentence Final Particle le (SFP) at the end of the sentence. However, differently from the sentence in (25), the one in (26a) has a continuative reading. When the sentence is produced, it is very likely that Lisi still lives in Beijing. Moreover, the sentence in (26b) only contains Sentence Final Particle le but not perfective -le, nevertheless, the sentence still has a continuative reading. I take this as an indication that the sentential le is the grammatical element which contributes to the continuative reading. In other words, a sentence that has a stative event and a durative adverb such as wu nian '(for) five years' along with perfective -le should not be translated into an English sentence containing the perfect construction given that no continuative reading is conveyed.

In addition to the continuative reading that is conveyed by the perfect construction, the 'resultative' reading is another possible additional reading in a sentence containing the perfect construction in English. The sentence in (12b), repeated as (27) is an example:

(27) Mary has read Dream of the Red Chamber. (Resultative Perfect) 
As discussed, the sentence in (27) has a resultative perfect reading in which Mary's reading of the novel has caused some result and some effect upon the current situation. I now use the three sentences in (28) to test whether or not -le has the same pragmatic implication.

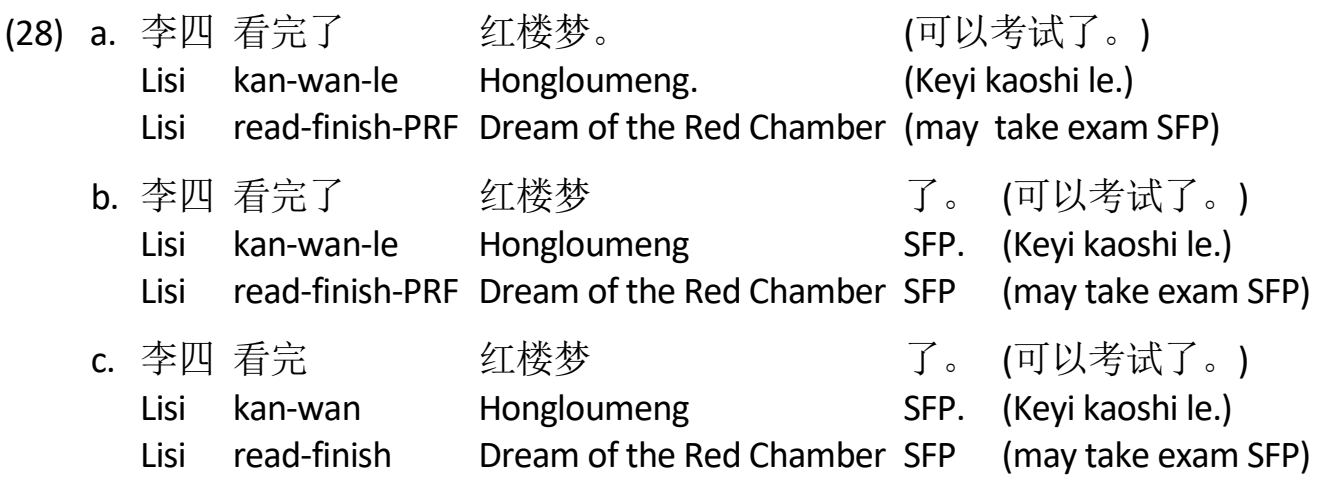

a-c. 'Lisi has read DRC; (therefore, he may take the exam now).'

The three sentences in (28) each contains an event denoting accomplishment, namely, Lisi's completion of reading Dream of Red Chamber. However, they contain different grammatical elements. The sentence in (28a) does not have the Sentence Final Particle le and (28b) and (28c) do. Also, differently from (28c), (28a) and (28b) both include perfective -le. In addition, I added a second sentence keyi kaoshi le 'may take the exam (now)' to each sentence to create a cause-result relation. If the first sentence has a resultative reading, then the second sentence would be fallacious due to the cause-result effect. This then provides the linguistic environment in which the resultative reading can be tested; therefore, Lisi's being able to take the exam resulted from his completion of the novel.

As demonstrated, the first sentence in (28a), which contains only perfective -le does not have a cause-result relation with the following sentence. In fact, the sentence sounds odd if we place the second sentence after it. However, the two sentences in (28b) and (28c), with Sentence Final Particle le, tell a different story. They both have a cause-result relation with the following sentence. This indicates that Sentence Final Particle le is the element which contributes to the cause-result relation. Therefore, I take it as an indication that perfective -le in Mandarin Chinese does not have the same pragmatic function as English perfect construction; at least, in the area of expressing cause-result relation between two events.

The two examples provided in this sub-section suggest that Chinese perfective -le does not have similar pragmatic functions as English perfect construction although these two grammatical items both have the same temporal contribution; that is, they both indicate an after relation between two temporal intervals. 


\subsection{Discussion}

In sections 3-1 and 3-2, I presented the main semantic function of perfective -le. In the spirit of Demirdache \& Uribe-Etxebarria's $(2007,2014)$ work, I argued that the suffix builds up a temporal relation between two different events; it indicates that one event occurs after the other. This 'anterior' relation is in fact like one of perfective -le's functions discussed in Li and Thompson's (1981, p. 198) study. According to them, in a sentence such as (29), the suffix appears in the first event in a sequence and the sentence can often be translated with 'after', 'when', or 'now that' in English:

(29) 我 看完了 $\quad$ 报, $\quad$ 就 睡。
Wo kan-wan-le bao, jiu shui
I read-finish PRF newspaper then sleep
'When I finish reading the paper, I will go to sleep.'

However, this function in fact can be extended to other types of sentences containing perfective -le discussed in Li and Thompson's (1981) study as well. According to them, the suffix can appear in the following types of sentences. (a) A sentence containing a quantified event. (b) A sentence having a definite or specific event. (c) A sentence containing verbs with an inherent bounded meaning. The sentences in (30) give a demonstration:

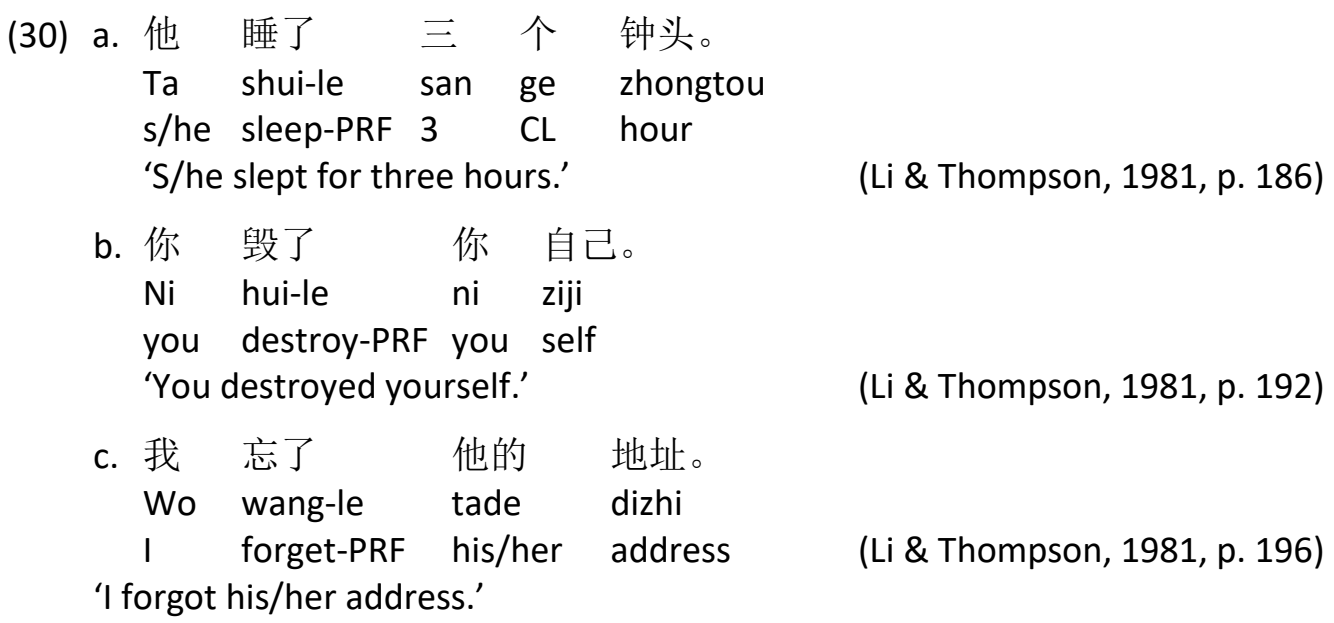

As demonstrated, each sentence in (30) provides a special environment in which -le can appear. In (30a), the sleeping event is quantified as the period of the sleeping event is specified. In (30b), the direct object is a pronoun and therefore, the selfdestroying event is definite. Finally, the verb wang 'forget' in (30c) has an inherent bound meaning. Although the linguistic environments are different in these sentences, perfective -le here builds up the same temporal relation: it indicates that all the events have occurred before the sentences are produced. 
Nevertheless, a bound event for the use of perfective -le is crucial as argued by Li and Thompson (1981). This can explain why in a sentence such as (1a), repeated as (31a), perfective -le is required but not in (1b), repeated as (31b) below:
a.
昨天
在家
写了
Wangwu
zuotian
zai jia xie-le
'Wangwu wrote one letter at home yesterday.'
Wangwu yesterday at home write-PRF one $\mathrm{CL}$ letter
b. 王五 昨天 在家 写 信。
Wangwu zoutian zai jia xie xin.
Wangwu yesterday at home write letter
'Wangwu wrote letters at home yesterday.'

一封信。

yi feng xin.

As shown, both sentences are used to express some action that occurred before the speaking event; that is, the time when the sentence is produced. In (31a), perfective -le is used as the letter-writing event is specific and bound, and the perfective suffix also indicates that there is another event that occurs after the letter-writing event; that is, the event of speaking. In contrast, the sentence in (31b) does not contain perfective -le although the sentence is also used to describe some action that happened yesterday. However, the main event, xie xin 'write letter(s)' in (31b) differs in that it is a verb that denotes Activity. Other examples of verbs that denote Activity in Chinese include tiao wu 'jump dance: to dance', chi fan 'eat rice: to eat,' and many others. Given that the sentence does not contain a bound event (i.e., events denoting Accomplishment of Achievement), perfective -le may not be used based on Li and Thompson's (1981) argument. The incompatibility between perfective -le and unbound events entails that -le appears only when the semantic requirements are met. First, the event that -le modifies must be bound. Secondly, there must be another event that occurs afterwards as perfective -le builds up an after relation between two events.

I've also discussed proper English translations of Chinese perfective -le. As argued, the suffix builds up an after relationship between two different events. This relation is in fact the same as the function of the past tense or the perfect, which also builds up an after relation based on Demirdache and Uribe-Etxebarria's studies (2004, 2007, 2014). According to the authors, past tense indicates that the reference time (the RFT-T) occurs after the assertion time (the AST-T) and the perfect indicates that the assertion time (AST-T) is after the event time (EV-T). Given that -le also builds up an after relation, it seems plausible to assume that a sentence with this suffix can be translated into an English sentence with either the past tense or the perfect construction. However, in addition to its semantic function, the English perfect also has additional pragmatic effects as claimed by previous studies such as Portner (2003). Unless Chinese perfective -le also has similar pragmatic effects, past tense is in fact a better translation. As I have shown, perfective -le in Chinese does not have similar pragmatic functions as the English perfect construction; therefore, I suggested that the perfect construction (at least, the present 
perfect) is not a good translation for sentences containing this suffix unless there are other elements like Sentence Final Particle le that have similar pragmatic contributions.

\subsection{Pedagogical implications}

In this sub-section, I present some pedagogical issues regarding perfective -le in a CFL/CSL classroom. As shown in section 2.2, the function of perfective -le remains the same in different temporal situations. It indicates that an event occurs, has occurred, or will occur after the event that the verbal suffix -le is used to modify. Therefore, I suggest that we give a short introduction of the temporal relation built up by -le as shown by the chart in (18), repeated as (32) below:

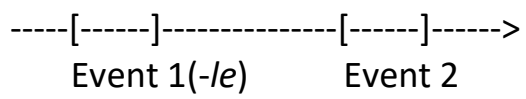

The chart in (32) gives a clear definition of the temporal function of perfective -le. Syntactically, the suffix is attached to the verb, which denotes a bound event (Event 1). Semantically, the suffix indicates that there is another event (Event 2) that appears after Event 1. This introduction will provide CFL learners with a clearer idea of the core function of the verbal suffix. I would also like to suggest that there is no need to introduce conplex grammatical terms such as the perfective aspect or the perfect construction in the classroom. These terms can be confusing and may even cause misunderstanding of the core function of the verbal suffix. For example, I have demonstrated that although the temporal relations built up by the perfective aspect and the perfect construction are similar, they are not identical.

As far as the interpretation of a sentence with the verbal suffix is concerned, we can leave it to students to discover the correct translation in the contexts. There is not a so-called "fixed" interpretation for a given sentence with perfective -le because the interpretation mainly depends on the various contexts it is found. For example, if perfective -le is used in a sentence to describe two events in a sequence in the future, English future perfect can be properly used to translate this type of sentences. However, if we use English present perfect to translate a sentence with perfective -le, the interpretation may sometime be incorrect as this suffix does not have the same pragmatic functions as English prefect construction. This suggests again that the context in which a sentence with perfective -le determinates the interpretation of the sentence.

To make the usages of -le more salient to CFL/CSL learners, l'd like to suggest that a handout that explains the usages of perfective -le be distributed in class. In addition, I suggest the handout should include Table 1 below, which has examples demonstrating the functions of perfective -le in different situations. 
Table 1: The functions of perfective -le and examples

Examples

Function

1. 李四昨天看了那个电影才回家。

Lisi zuotian kan-le na ge dianying cai huijia

Lisi yesterday watch-PRF that $\mathrm{CL}$ movie then return home

(past; time words)

'Lisi went home after watching that movie yesterday.'

2. 李四昨天看了那个电影。

going home after watching

movie

Lisi zuotian kan-le na ge dianying

Lisi yesterday watch-PRF that CL movie

(past; time words)

speaking after watching

movie

'Lisi watched that movie yesterday.'

3. 李四看了那个电影。

(past; no time words)

Lisi kan-le na ge dianying

speaking after watching

Lisi watch-PRF that CL movie

movie

'Lisi watched that movie.'

4. 李四明天看了那个电影才回家。

Lisi mingtian kan-le na ge dianying cai huijia

(future; time words)

going home after watching

Lisi tomorrow watch-PRF that $\mathrm{CL}$ movie then return home

movie

'Lisi will go home after watching that movie tomorrow.'

As can be seen, Table 1 contains sample sentences including perfective -le used in different situations. Each example includes a sentence in Chinese, its word-by-word translation, and the literal translation. The table also includes the functions of perfective -le in each example. As shown, the suffix is mainly used to express an after relation between two events. However, in Examples 1 to 3, the suffix is used in a past situation and in Example 4 it is used in a situation that will happen in the future.

\section{Conclusions}

In this study, I have addressed two questions concerning perfective -le in Mandarin Chinese. The first one concerns the main semantic function of perfective -le. I followed studies like Klein (1994) and Demirdache and Uribe-Etxebarria $(2004,2007,2014)$ and argued that the suffix has an ordering function like tense and aspect. However, instead of ordering different types of temporal intervals, I argued that perfective -le simply orders two different events. I demonstrated that when a sentence contains two salient events, perfective -le indicates that one event occurs after the other. With the same ordering function, when a sentence contains only one salient event, perfective -le indicates that the speaking event is after the main event expressed by the sentence. 
The second issue that I have addressed in this study is the proper English translation of perfective -le. I discussed the difference between the two grammatical items that are related to time: the perfective aspect and the perfect construction. I demonstrated that a sentence containing perfective -le does not have the same pragmatic functions as the English perfect, particularly, the English present perfect although these two grammatical items have similar semantic functions. For example, a sentence containing both the perfective suffix and a verb denoting a stative event has a continuous reading only if Sentence Final le also appears in the same sentence; perfective -le does not have the same pragmatic contributions. This finding suggests that a sentence containing perfective -le should not be translated into English present perfect when it is used to describe a past event.

Based on the proposal I made, I also presented a number of pedagogical suggestions regarding perfective -le. For instance, I suggested that the use of handouts would facilitate CFL/CSL learners' acquisition of different grammatical patterns. The handouts should include not only the functions of the suffix, but sample sentences that demonstrate the situations in which -le is used. In addition, I have suggested that we should not use complex terms in English such as perfective or the perfect to instruct grammar in CFL/CSL class.

\section{References}

Arche, M. (2014). The construction of viewpoint aspect: the imperfective revisited. Natural Language \& Linguistic Theory, 32, 791-831.

Chao, Y. R. (1968). A grammar of modern spoken Chinese. Berkeley and Los Angeles, University of California Press.

Comrie, B. (1976). Aspect: An introduction to the study of verbal aspect and related problems. New York: Cambridge University Press.

Cook, V. (2001). Using the first language in the classroom. Canadian Modern Language Review. 57 (3), 402-423.

Demirdache, H., \& M. Uribe-Etxebarria (2007). The syntax of time arguments. Lingua, 117, 330366.

Demirdache, H., \& Uribe-Etxebarria, M. (2000). The primitives of temporal relations. In R. Martin, D. Michaels \& J. Uriagereka (Eds.), Step by step: Essays on minimalist syntax in honor of Howard Lasnik (pp. 157-186). Cambridge: The MIT Press.

Demirdache, H., \& Uribe-Etxebarria, M. (2004). Syntax of time adverbs. In J. Gueron. \& J. Lecarme. The syntax of time. Cambridge: The MIT Press.

Demirdache, H., \& Uribe-Etxebarria, M. (2014). Aspect and temporal anaphora. Natural Language \& Linguistic Theory, 32, 855-895.

Duff, P., \& Li, D. (2002). The acquisition and use of perfective aspect in Mandarin. In R. Salaberry \& Y. Shirai (Eds.), The L2 acquisition of tense-aspect morphology (pp. 417-453). Amsterdam/Philadelphia: John Benjamins Publishing Company. 
Giorgi, A., \& Pianesi, F. (1998). Tense and Aspect: From Semantics to Morphosyntax. Oxford: Oxford University Press.

Huang, J., Li, D., \& Li, A. (2009). The syntax of Chinese. Cambridge: Cambridge University Press. $\mathrm{Ke}, \mathrm{C}$. (2005). Acquisition patterns of Chinese linguistics features for CFL learners. Journal of the Chinese Language Teachers Association 40(1), 1-24.

Klein, W. (1994). Time in language. London: Routledge.

Li, C., \& Thompson, S. (1981). Mandarin Chinese: A functional reference grammar. Berkeley and Los Angeles: University of California Press.

Lin, J.-W. (2003). Temporal reference in Mandarin Chinese. Journal of East Asian Linguistics, 12, 259-311.

Ljungqvist, M. (2007). Le, guo and zhe in Mandarin Chinese: a relevance-theoretic account. Journal of East Asian Linguistics, 16(3), 193-235.

Petrovčič, M. (2009). Operator LE in Chinese. Complexity within simplicity and simplicity within complexity. VDM Verlag.

Portner, P. (2003). The (temporal) semantics and (modal) pragmatics of the perfect. Linguistics and Philosophy, 26, 495-510.

Shi, Z. Q. (1990). Decomposition of perfectivity and inchoativity and the meaning of the particle LE in Mandarin Chinese. Journal of Chinese linguistics, 18(1), 95-123.

Smith, C. S. (1997). The parameter of aspect. Dordrecht: Kluwer.

Soh, H. L., \& Gao, M. J. (2007). It's Over: Verbal-le in Mandarin Chinese. In A. Hedberg, R. Zacharski \& G. K. Gundel (Eds.), The grammar-pragmatics interface (pp. 91-109). Amsterdam/Philadelphia: John Benjamins Publishing Company.

Stowell, T. (1996). The phrase-structure of tense. In J. Roorych \& L. Zaring (Eds.), Phrase structure and the lexicon (studies in natural language and linguistic theory) (pp. 277-291). Dordrecht: Kluwer.

Stowell, T. (2007). The syntactic expression of tense. Lingua, 117(2), 437-463.

Sybesma, R. (1999). The Mandarin VP. Dordrecht: Kluwer.

Teng, S. (1999). The acquisition of "le" in L2 Chinese. World Chinese Teaching and Learning (originally in Chinese), 47, 56-64.

Travis, L. (2005). Articulated vPs and the computation of aspectual classes. In P. Kenpchinsky, \& R. Slabakova (Eds.), Aspectual inquiries (pp. 69-94). Dordrecht: Springer.

Travis, L. (2010). Inner aspect: The articulation of VP. Dordrecht: Springer.

Vendler, Z. (1967). Linguistics in Philosophy. Ithaca, NY: Cornell University Press.

Wells, G. (1999). Using L1 to master 12: a response to Antón and DiCamilla's Socio Cognitive Functions of L1 Collaborative Interaction in the L2 Classroom. The Modern Language Journal, 83(2), 248-254.

Wen, X. (1997). Acquisition of Chinese aspect: An analysis of the Interlanguage of Learners of Chinese as a Foreign Language. ITL, Review of Applied Linguistics, Dec, 1-26.

$\mathrm{Wu}$, Z. (2004). A minimalist approach to the re-grammaticalization of morphology. In P. Pica (Ed.), Linguistic variation yearbook 4 (pp. 261-297). Amsterdam/Philadelphia: John Benjamins Publishing Company. 